Emir. J. Agric. Sci. 2003. 15 (2): 1-16

http://www.cfs.uaeu.ac.ae/research/ejas.html

\title{
Linking food systems to human nutrition needs: the nutrition transition in the United Arab Emirates
}

\author{
K. S. Kubena \\ Texas A\&M University \\ College of Agriculture and Life Sciences, 2402 TAMU \\ College Station, TX 77843-2402, U.S.A.
}

\begin{abstract}
Early recommendations for dietary intake of nutrients in humans focused upon nutritional deficiencies and their prevention. More recent recommendations were based on research that demonstrated relationships between nutrients and other dietary components and chronic disease. The study of genomics eventually will allow delineation of particular genes that are related to the development of disease and that vary in their responsiveness to intake of dietary components. The wealth of information on the role of dietary intake in optimal health from the whole organism to submolecular levels should promote optimal nutrition in newly developed countries in which food supply is adequate for all people, that is the nutrition transition has occurred there. However, inappropriate nutrition and the chronic diseases that are at least in part its result are increasing at epidemic proportions in many areas in the world. Obesity and type 2 diabetes mellitus are considered to be the result of lifestyle changes that include excessive energy intake and physical inactivity. Control of diabetes and hypertension can be prevented or improved significantly by modification of dietary intake and exercise. Data are accumulating about the involvement of nutrients and other dietary components in the development and treatment of cancer at various sites. Dietary intake affects maintenance of health and avoidance of disease across the life cycle. Efforts should be directed toward promoting a food supply that contributes adequate amounts of nutrients and other dietary components, such as phytochemicals and fiber, which are helpful in maintaining optimal health and in delaying or preventing chronic disease. Biotechnology can be used to improve crop yield and to enhance nutritional value and content of substances, such as phytochemicals, in foods. Achieving the goal of optimal nutrition and health for all requires efforts of the food system, from biotechnology and production, to processing, distribution, and marketing.
\end{abstract}

Key words: dietary intake, dietary components, chronic diseases

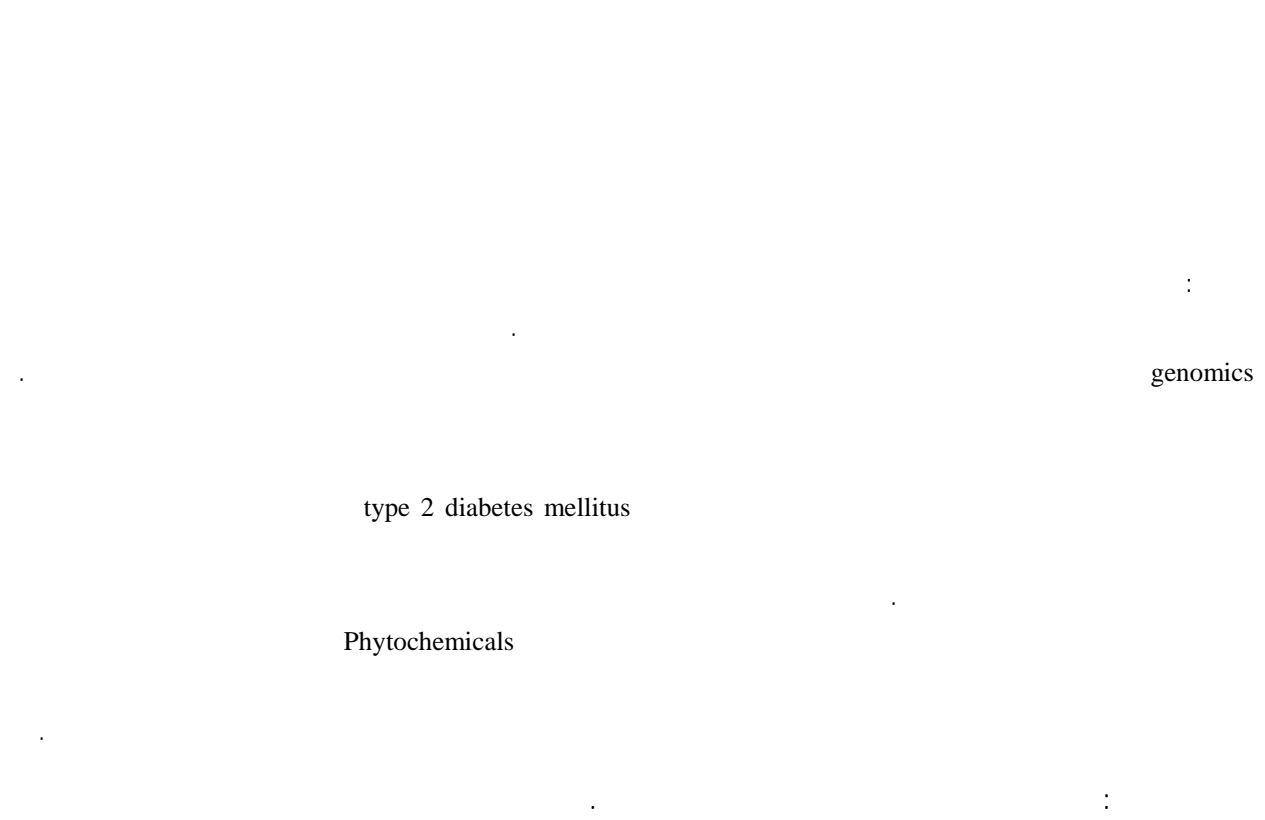




\section{Introduction}

The development of agriculture, which facilitated the evolution of civilization, also allowed the hunter-gatherer of the ancient world to stay at home to grow and then store crops for the future. Therefore, the varied diet of the active hunter-gatherer changed to a less diverse one for sedentary families (Heber and Bowerman 2001). As life has continued to become more convenient, in many ways, quality of diet has deteriorated and diet-related health problems have increased.

The incidence of chronic noncommunicable diseases, so many of which are related to diet and nutrition, is increasing worldwide. Occurrence of cardiovascular disease and other chronic diseases that have been concerns in "affluent" countries for some time are appearing in developing countries and coexist in the latter with undernutrition in some subgroups of the population. A 2002 report of the changes in diet and nutrition in Egypt indicated that dietary energy is abundant, and prevalence of obesity, hypertension and diabetes in adults is very high. Nevertheless, childhood malnutrition continues at previous rates (Galal 2002). Within 20 years, chronic disease may account for up to $75 \%$ of all deaths worldwide (Joint WHO/FAO Expert Consultation on Diet, Nutrition and the Prevention of Chronic Diseases 2003).

Coronary heart disease risk factors were investigated in a rural population of Bedouin origin in the UAE. Results indicated that the prevalence of diabetes was $6 \%$ in males and $7 \%$ in females, $27 \%$ of all urban residents were obese (BMI $\geq 30$ ), 19-25\% had systolic hypertension, and diabetes was related to elevated systolic and diastolic blood pressure (el Mugamer et al., 1995). Data from the Ministry of Health of the United Arab
Emirates in 1998 indicate that two of the three leading causes of death were cardiovascular diseases (number 1) and cancer (number 3) (Badrinath et al., 2002). Both of these are chronic diseases the development of which can be modified by changes in diet and lifestyle. According to the report, almost $25 \%$ of adult Emirates had hypertension, and the prevalence of diabetes mellitus among Emirate adults was 10.4\% (Badrinath et al., 2002).

The objectives of this paper are to review how food intake has changed in those countries that recently have become economically developed, particularly the United Arab Emirates, and what recommendations have been made to optimize health throughout the life cycle.

\section{Food Consumption}

Economic development improves the food supply of a country so that nutrient deficiencies can be eliminated. The term "nutrition transition" describes changes in diet and nutrition because of changes in economic, social, demographic, and health factors (Popkin, 1993). Characteristic of these changes include a higher intake of fat and added sugars, more animal products and thus saturated fat, and less complex carbohydrates, dietary fiber, fruits, and vegetables. (Drewnowski and Popkin, 1997).

In 1990, the Food and Agricultural Organization of the United Nations compared data on foodstuffs available in countries around the world with similar data from 1960 (World Cancer Research Fund, 1997). Globally, trends included lower consumption of cereal foods while the use of added fats, meat, dairy products, and alcohol increased. Data for Middle East Asia in 1990 indicated that consumption of cereals provided approximately $55 \%$ of total dietary energy while those in high-income countries 
received 40\% dietary energy from this food group. According to the FAO analysis, since 1960 a marked increase in fat consumption has taken place in the Middle East as the diet has become more diverse. Meat consumption, which represented 4\% energy across the region in 1960, increased to 11 $12 \%$ in countries of the Arabian Peninsula. Intake of milk and dairy products remained fairly low. In higher income areas of the region, intake of vegetables and fruits increased but still represented less than $10 \%$ of dietary energy. Intake of total dietary fat was fairly low overall although data for Kuwait and other high-income countries indicated a consumption of more than 30\% energy from this source. Sugar and other sweeteners provided up to if not more than $10 \%$ total energy intake (World Cancer Research Fund, 1997).

The 2003 report from the FAO/WHO summarized more recent data on diet (Joint WHO/FAO Expert Consultation on Diet, Nutrition and the Prevention of Chronic Diseases, 2003). Over the past three decades, availability of animal protein has tripled in industrialized countries while intake of cereals has decreased slightly in developing countries. The supply of dietary fat has risen worldwide, and the proportion of energy supplied by fat is more than $30 \%$ in most industrialized countries and is increasing in almost all other areas. Vegetable oils are more evident in diets in poor countries. Consumption of meat, milk, and eggs as substitutes for staple foods is higher than it was a couple of decades ago. With urbanization, people are further away from the source of production of fruits and vegetables, which limits access to these foods (Joint WHO/FAO Expert Consultation on Diet, Nutrition and the Prevention of Chronic Diseases, 2003).

Food selection is determined by socioeconomic characteristics, such as income and religion; food beliefs and attitudes; health status and lifestyle; and food availability. As these aspects of the person's life change, food selection changes as well (Shatenstein and Ghadirian, 1998). Factors that were associated with recent alterations in food consumption in Arab countries were discussed by Musaiger (1993). Substantial increases in income from oil revenues especially during the 1970's resulted in the ability to obtain foods that previously had not been available to many people in the region. Changes in food intake were led by giant increases in meat consumption (almost $500 \%$ in Saudi Arabia) followed closely by those for milk. Use of eggs and cereals also increased significantly. These changes occurred first in high-income groups although those with lower incomes strove for such changes when their income increased (Khaldi, 1984).

Governmental policy through subsidies for specific foods plays a role in food availability. Musaiger stated that such support for specific foods, such as meat, rice, wheat flour, sugar and oil in the Arab Gulf countries during the 1970's and 1980's encouraged intake of these foods (Musaiger, 1993). Availability of foods is affected by the locale, i.e., agricultural production or fishing in the area or urbanization (Musaiger, 1993). Since the overwhelming majority of the population in Arab countries is Muslim, food consumption is influenced by Islamic food law. Religious observances such as Ramadan, significantly affect food intake at these times (Shatenstein and Ghadirian 1998; Eliasi and Dwyer 2002). Migration of workers and others among Arab countries and from non-Arab regions over the past two decades brought food preferences along with the people (Musaiger, 1993). It has been stated that distribution of food within families varies in the region based upon age and gender. This fact was 
suggested as the cause of lower nutritional status of girls in the Arab region in a UNICEF report (Musaiger, 1993). People in Arab countries, as in the rest of the world, have beliefs about foods that are based upon traditions or folk beliefs and that may have little basis in science. Educational level in general, knowledge of nutrition and foods, women's employment outside of the home, and mass media have affected dietary intake in Arab countries as they have in countries around the world.

Musaiger and Abuirmeileh (1998) reported results of a 1993 survey of more than 2,000 subjects in the United Arab Emirates. Evidence from this investigation supports the conclusion that changes in dietary intake in the UAE are similar to those noted in the FAO analysis. Traditional foods, e.g., fish, laban (diluted yogurt) and rice, were used more by older than younger men. Older women drank more milk than younger women. Another factor that was related to the use of less traditional foods was education level. Subjects with higher education levels, men and younger subjects, replaced traditional foods with eggs, cheese, and chicken (Musaiger and Abuirmeileh, 1998).

Food composition data for foods commonly used in Arabian Gulf countries are being published (Musaiger 1994; Musaiger, et al., 1997; Dashti et al; 2003). A 1998 report of analysis of some traditional items in Oman indicated that the foods were low in dietary fiber, high in sodium, low in iron and zinc, and, in comparison to reports from other Arab Gulf countries, higher in fat (Musaiger, et al., 1997). Because many of the dishes included vegetables as an important component, results for fiber were surprising. However, this apparent inconsistency was explained by the fact that most vegetables are peeled before cooking. Sources of sodium were not only salt added while cooking, but also some of the spices used, including coriander leaf, cloves, and cumin (Murphy et al., 1978).

\section{Nutritional Throughout the Life Cycle}

Origins of chronic disease that manifest in adulthood have been observed in adolescence and may be traced to conditions during fetal life. Genes, which affect susceptibility to development of chronic disease, can be influenced by environmental factors, such as nutrients and physical activity. Although genes can be identified for individuals that indicate the likely influence of dietary components and other factors on the development of disease, developing a dietary prescription for an individual based upon this information likely will not be possible for a long time (Young, 2002). It is a complex problem. Nevertheless, opportunities to affect development of disease exist throughout the life cycle.

Pregnancy. Birthweight of the infant is determined by maternoplacental transfer of nutrients, a reflection of weight gain of the mother during pregnancy (substrate availability in maternal circulation) and her prepregnancy weight (placental size), although other factors, such as maternal fetal growth, may play a role as well (Barker, 1998; Kaiser and Allen, 2002). A hypothesis has been proposed that suggests hormonal and nutrient changes in the intrauterine environment may have a permanent effect on the structure and function of fetal systems and thus predispose individuals to chronic disease later in life (Godfrey and Barker, 2000). The fetal origins hypothesis is supported by studies in adults with either low birthweight or very high birthweight and the occurrence of coronary heart disease, hypertension, and type 2 diabetes (Frankel et al., 1996; Plagemann et al., 1997; Galtier- 
Emir. J. Agric. Sci. 2003. 15 (2): 1-16

http://www.cfs.uaeu.ac.ae/research/ejas.html

Dereure et al., 2000; Godfrey and Barker, 2000).

Even if the size of the infant at birth is not affected, as observed in individuals who were conceived or born during the Dutch hunger winter, health of the individual in adulthood may be permanently altered (Roseboom et al., 2001). Congenital anomalies have been reported to be related to nutrient availability, an example of which is the role of folic acid and/or vitamin B12 in neural tube defects (Czeizel and Dudas, 1992; Bunduki et al., 1995; Mills et al., 1995). A survey was done in Al-Ain, United Arab Emirates (UAE) to identify prevalence of pre-conception folic acid intake among women and factors related to its use. Results indicated that less than $10 \%$ of women in the reproductive age took folic acid prior to conception, about the same percentage as those who had heard that such a supplement was related to the prevention of neural tube defects. Surprisingly, non-UAE nationals and those with less education were more likely to take these supplements than others (Abdulrazzaq et al., 2003). Another nutrient of concern during pregnancy is vitamin D. Low vitamin D status of mothers is associated with neonatal hypocalcemia and impaired fetal bone growth (Dawodu et al 1998). A study conducted in Al-Ain identified vitamin $D$ insufficiency of women - UAE nationals (24\%), non-Gulf Arabs (12\%) and Europeans (0\%). Differences were attributed primarily to the degree of coverage of skin by traditional clothing of UAE nationals. Another risk factor during pregnancy is iron deficiency anemia. In 1992 and 1993 iron status of 309 children and their mothers in Al-Ain and Abu Dhabi Emirate was assessed. Anemia was found in $14 \%$ of pregnant women and $16 \%$ of nonpregnant women (Hossain et al., 1995).

Low birthweight infants (LBW) are considered to be high risk for morbidity and mortality. A study of factors associated with LBW infants born to indigenous women in UAE found that mothers tended to be younger and were likely to have given birth to previous LBW infants or twins (Abdulrazzaq et al., 1995). Multiple logistic regession analysis of sociodemographic factors in this population found that maternal smoking, antenatal care, lack of help in the home and mother's occupation were associated with LBW (Bener et al., 1996). According to a position statement of the American Dietetic Association, primary components of a healthy lifestyle for pregnant women include appropriate weight gain, consumption of an adequate amount of high nutrient density foods, and vitamin and mineral supplements as needed (Kaiser and Allen, 2001).

Breastfeeding. Human milk provides a nutrient profile that is ideal for human infants and that changes with their changing nutritional needs. Some nutrients in the milk are affected by maternal diet. An investigation of hypovitaminosis $\mathrm{D}$ in exclusively breast-fed infants and their mothers was conducted in Al-Ain, UAE, during the summer. Results indicated that $61 \%$ of mothers and $82 \%$ of the infants tested had hypovitaminosis $\mathrm{D}$, a strong indication of need for vitamin $D$ supplementation of infants (Dawodu et al., 2003). Inadequate intake of vitamin D by mothers along with the lack of skin exposure to ultraviolet radiation from the sun likely played key roles in this development.

Immunologic properties of human milk cannot be duplicated in infant formulas and provide a measure of protection from pathogens in the environment that is also unmatched. Research is underway to assess impact of breastfeeding on the development of future disease (Kaiser and Allen 2001). Studies indicate that breastfed infants may have lower risk for development of 
inflammatory bowel disease, celiac disease, type 1 diabetes, certain types of childhood cancer, and obesity during childhood and hypertension and cardiovascular disease as adults (Shu et al., 1999; von Kries et al., 1999; Raisler et al., 1999; Dietz, 2001; Singhal, 2001).

With few contraindications to breastfeeding and increasing evidence of benefits for infants now and in the future, the need exists to encourage breastfeeding by all women (Kaiser and Allen, 2001). The prevalence and length of breast feeding has been studied over the past decade in UAE. A 1991 study indicated that breastfeeding was continued an average of 4.5 to 5 months in urban mothers in Dubai and 9 months by rural mothers in that area (Shahraban et al., 1991). In 1997 a 4-week study of 221 breastfeeding mothers in Al-Ain was done. Although 100\% initiated breastfeeding and all continued for the duration of the study, only $4 \%$ provided only human milk; all others added water, tea, juice or herbal beverages (yansun or babunj) (al-Mazroui et al., 1997). By a 1999 study again conducted in Al-Ain, $46 \%$ of the 300 healthy infants were breastfed for 4-6 months. Fresh cow and goat milk were the most common supplements to human milk although baby formula was often added early perhaps because of advertising (Osman and elSabban, 1999). A study in Fujairah UAE revealed an $83 \%$ rate of initiation of breastfeeding with $73 \%$ and $47 \%$ continuing at 2 and 6 months, respectively (Sharief, Margolis and Townsend 2001). In contrast to studies in Western countries, the rate of breastfeeding in this one decreased as education level of the mother increased. Ironically, as the rate and duration of breastfeeding was falling in these investigations, a 2001 report of a casecontrol study conducted in Al Ain, UAE, demonstrated a protective effect of breastfeeding longer than 6 months against childhood leukemia and lymphomas (Bener, Denic and Galadari, 2001).

Food selection during lactation is important to prevent depletion of the mother's nutrient stores, but food beliefs often play a role. Food composition analysis revealed that the primary foods by tradition consumed during puerperium by women in Oman, were high in energy but low in nutrients, such as high quality protein, iron and zinc (Musaiger et al., 1998). Of interest is a recent study that revealed a lack of affect of fasting during the holy month of Ramadan on composition of breast milk produced by mothers in Al-Ain UAE (Bener et al., 2001).

Infancy. Human milk provides adequate nutrient and energy for the infant during the first four to six months of postnatal life. Iron supplements are needed at this time since the reservoir of iron in fetal hemoglobin present at birth has been replaced by mature hemoglobin that contains less iron. Results of a study of Arab infants and young children in UAE were consistent with other reports of widespread hypovitaminosis D in children and their mothers. Infants who received supplements of vitamin $\mathrm{D}$ had notmal levels in their blood (Dawodu et al., 2001).

Delaying introduction of culturally appropriate complementary foods beyond six months of age point may reduce acceptance of new tastes and textures by the infant. Commercial formulas are available that provide safe and adequate nutrition to infants who cannot be or are not breastfed. Infants have excellent appetite control, and parents should trust indications of satiety by the infant. Overriding the infant's appetite control is common in developed countries with tactics such as food rewards.

Investigations of growth during infancy point to the need for adequate weight gain in the first year of postnatal life. Inadequate 
Emir. J. Agric. Sci. 2003. 15 (2): 1-16

http://www.cfs.uaeu.ac.ae/research/ejas.html

growth at this time is associated with elevated blood pressure and central fat accumulation (abdominal obesity) in childhood and coronary heart disease as adults (Barker et al., 1989; Eriksson et al., 2001; Walker et al., 2001; Walker et al., 2002). On the other hand, excess growth and short stature were related to stroke and cancer at certain sites in studies of adults (Must and Lipman, 1999; Eriksson et al., 2000). Maintenance of a normal rate of growth during infancy is needed.

Childhood and adolescence.

Development of food habits occurs in early childhood, many of which have been shown to track into later childhood, adolescence, and adulthood. Children learn about food acceptance and physical activity by watching role models, i.e., parents, siblings, and peers. It has been suggested that parents or caregivers are responsible for providing nutritious foods for children while children are responsible for deciding what and how much will be eaten.

Dental caries begin to appear in childhood after primary teeth erupt. Convincing evidence exists that dental erosion and thus dental caries are related to the amount and frequency of intake of monosaccharides or disaccharides. With the exception of lactose and its lower risk, cariogenicity of other simple sugars is quite similar (Joint WHO/FAO Expert Consultation on Diet, Nutrition and the Prevention of Chronic Diseases, 2003). Energy content of concentrated sugars is high although other nutrients are low or absent. Therefore, they can be eliminated to reduce the energy content while the nutrient level overall remains high.

Iron deficiency anemia is the most common nutritional deficiency in children. In a study of iron status of women and their children in UAE, a total 3\% of children aged $1-2$ months, $8 \%$ 3-5 months, and $25-39 \% \geq 6$ months were anemic (Hossain et al., 1995). A 1996 report of a study of 6-year-old school children across the UAE indicated that $31 \%$ had anemia by the WHO criterion of $<12 \mathrm{~g}$ hemoglobin/dl (Musaiger et al., 1996). Because of the greatly improved socioeconomic status in UAE over the past few years, the high rate of anemia was disappointing to these authors.

An epidemic of childhood obesity is occurring in the United States and in many other countries (Dietz et al., 2002). The use of several factors to predict children who are at high risk of developing obesity was suggested by George Bray: (1) overweight parents; (2) early age of adiposity rebound, defined as the age at which the turning point occurs from decreasing BMI as children grow in length faster than their weight increases to increasing BMI, usually between age 5 and 7 years; (3) infants of mothers who develop gestational diabetes; and (4) infants of mothers who smoked during pregnancy (Bray, 2002). Tracking of childhood obesity into adolescence and adulthood varies among studies. Wright et al reported little tracking from childhood overweight to adult obesity when fatness was used rather than body size although children who were obese at age 13 had an increased risk of obesity in adulthood (2001). On the other hand, overweight children in China were 2.8 times as likely as normal weight children to become overweight adolescents (Wang et al., 2000). Factors related to persistence of obesity were parental obesity, dietary fat intake and family income.

Growth and dietary intake during childhood and adolescence have the potential to promote chronic disease in later life. A study of children begun in the late 1930's in Britain with a follow-up when they were adults demonstrated that the risk of cancer mortality was related proportionally 
to dietary energy intake (relative risk of 1.15 for every MJ increase in daily intake) (Frankel et al., 1998). A follow-up study to the Harvard Growth Study revealed risks associated with overweight in adolescence (Must et al., 1992). All cause mortality and especially death from coronary heart disease were increased in men but not women who had been overweight in adolescence. Risk of colorectal cancer and gout was increased in men and osteoarthritis in women who had been overweight adolescents.

Another epidemic is commanding attention, that of type 2 diabetes among children and adolescents (Pinhas-Hamiel and Zeitler, 2000). Rapid growth after 7 years of age in those with low birthweights was strongly related to the development of type 2 diabetes in a study of 7,086 subjects born in Finland between 1924 and 1933 (Forsen et al., 2000). The biologic basis for this phenomenon was suggested by Barker et al to be related to developmental plasticity and compensatory growth (2002). Type 2 diabetes was diagnosed in five adolescents in one hospital in Al-Ain, UAE, over an 8-year period, which was cause for concern on the part of these researchers that the epidemic of type 2 diabetes in adolescents had spread to this country (Punnose et al., 2002). Development of hypertension as adults was eight times as likely in adolescents with a BMI classified as overweight as in normal weight teens in a longitudinal study in Bogalusa, Louisiana. Almost 2.5\% of those adolescents who were overweight developed type 2 diabetes by the age of 30 in comparison to none of the normal weight adolescents (Srinivasen et al 1995).

Potential for increasing risk for developing osteoporosis begins in adolescence and may be related even to brief periods of food restriction during this period. About $45 \%$ of bone mass is gained during adolescence in addition to skeletal maturity that takes place during puberty. Adequate intake of calcium and other bone-building nutrients is needed at this critical time (Cadogan et al., 1997).

Adulthood. Obesity, physical inactivity, elevated LDL-cholesterol, hypertension, smoking, and use of alcohol are wellestablished risk factors for coronary heart disease (Joint WHO/FAO Expert Consultation on Diet, Nutrition and the Prevention of Chronic Diseases 2003). Increasing fruits and vegetables, reducing saturated fat and sugar, increasing intake of fish and seafood and reducing overall dietary energy intake while increasing physical activity can result in reduction of body weight, LDL-cholesterol, and blood pressure. Environmental factors that are associated with over consumption and a sedentary lifestyle usually are present and may interfere with adopting such a lifestyle. Encouraging the development of a healthy lifestyle beginning in childhood, which may track to adulthood, must be a long-term goal.

Obesity in the UAE has been reported to be very high in adults. A 1995 study of 215 female college students aged 18-30 years at UAE University found $29 \%$ of those studied to be overweight or obese (BMI $\geq 25$ ) (Musaiger and Radwan, 1995). Obesity was more prevalent in non-UAE nationals, and students whose mother did not have a maid. A study conducted the next year of 566 female students also at UAE University provided evidence that $10.8 \%$ of the students were overweight and $30.6 \%$ were obese (Amine and Samy, 1996). However, standards used in the latter study were percentage of relative body weight, a measure that has since been abandoned in favor of BMI. Nevertheless, prevalence of obesity in adults in the UAE is of concern. Factors related to obesity in the latter study were increasing age, being obese as a child, having obese parents, eating between meals, 
eating fast foods, and having limited physical activity plus afternoon napping.

A hypothesis that, like South Asians, Arabian peninsula men are more susceptible to insulin resistance was supported by a study of 358 multiethnic men in the UAE. Both groups had the tendency to have higher levels of glucose and insulin levels, lower HDL-cholesterol and more abdominal obesity than other groups (Pugh et al 1998). High susceptibility to insulin resistance suggest that control of obesity is extremely important in these groups. Acanthosis nigricans (AN) is a hyperpigmented cutaneous thickening on the back, sides of the neck, axillae and flexural surfaces that is often associated with diabetes. A study conducted in Al-Ain, UAE, revealed that female subjects with AN have a high prevalence of diabetes and insulin resistance and higher levels of several other hormones. A prevalent occurrence in the UAE, AN could be used to detect individuals with a high risk of diabetes (Bener et al 2001). Prevention of diabetes has been shown to be effectively done through voluntary weight loss if overweight and routine physical activity (Joint WHO/FAO Expert Consultation on Diet, Nutrition and the Prevention of Chronic Diseases, 2003).

Maintaining maximal bone mass throughout adulthood is also needed. Menopause triggers massive bone loss in women so that having accrued a high peak bone mass allows women to withstand this loss. Intake of calcium and other bonebuilding nutrients, weight-bearing exercise, and avoidance of excess caffeine and alcohol are helpful in preventing additional bone loss. Quantitative ultrasound (QUS) of the calcaneus, a measure of fracture risk shown to be as valid as axial bone mineral density (BMD), was done in Arabian women in AlAin, UAE. Results of the QUS and BMD revealed that the mean values were below the reference range of the manufacturer in each case, thus illustrating high risk of development of osteoporosis in this population (Saadi et al., 2003). Because of data demonstrating widespread hypovitaminosis $\mathrm{D}$ in UAE women and because the role of vitamin $\mathrm{D}$ in preventing osteoporotic fractures, this is not surprising (Joint WHO/FAO Expert Consultation on Diet, Nutrition and the Prevention of Chronic Diseases, 2003).

Older adults. Quality of life for older adults means reducing the potential for manifestation of chronic disease and preventing or delaying disability. Research over the last few years indicates that changing dietary intake and exercise patterns by older adults can have a significant effect on development and progression of chronic disease and, in many cases, maintaining independence (Jensen and Rogers, 1998; Anderson and Sjoberg, 2001). Information on health status of Emirates over the age of 65 in the UAE, representing only 1\% of the population, is lacking. The prediction for annual growth rate in those 65 years or older is the highest in the world. One of the first studies to provide information on this group indicated that elderly people living in the community of Al-Ain were quite healthy and supported by a high regard for traditional values, close family ties, universal religion and a high level of economic resources (Margolis et al., 2003). Nutritonal status, as determined by a survey of anthropometric, cognitive, and other data, was normal in $79 \%$ of this group of 184 .

Research is providing clues to the prevention of age-related loss of function. Adequate intakes of vitamins, minerals, and other dietary components may be able to prevent or delay development of cataracts and macular degeneration, loss of hearing, loss of cognitive function, osteopenia, and some other changes expected with advancing 
years. Reliance on food sources rather than nutrient supplements is recommended because of bioavailability of the substances as well as interaction with other biologically active compounds in the foods. Two exceptions to this dictum that are more bioavailable in supplement form than from foods are folic acid and vitamin B12.

\section{Recommendations to Reverse the Trend Toward Chronic Disease}

Chronic diseases that increase in countries as they undergo the nutrition transition are preventable by modifications in dietary intake. Demonstrating this concept is South Korea, a country that experienced rapid economic development and transition to what has been termed a Western lifestyle earlier than most other countries in Asia. At the same time, a series of national efforts to maintain the use of traditional foods, including mass media campaigns to promote use of local foods and a training program to teach people how to prepare traditional foods, was implemented (Kim et al., 2000). The extent to which these initiatives impacted dietary intake in that country is not known although people in South Korea have a lower intake of fat than would have been expected based upon the gross national product (GNP). Fat intake was strongly related to GNP in an analysis from 88 countries worldwide (Drewnowski and Popkin, 1997). Finland is another example this time of a country in which cardiovascular disease was epidemic in the 1960's. Prevention programs were mounted by the government and other organizations that were effective in reducing the mortality from ischemic heart disease 55\% in men 35 to 65 years of age (Vartianinen et al., 1999).

\section{Dietary Recommendations.}

The Joint WHO/FAO Expert Consultation on Diet, Nutrition and the Prevention of Chronic Diseases provided goals for dietary intake that are presented in the table below, data for which are based upon the Joint WHO/FAO report (2003).

Recommendations from the Joint WHO/FAO Expert Consultation on Diet, Nutrition and the Prevention of Chronic Diseases Report (2003) include the need for regular physical activity and a high intake of dietary fiber. There is less convincing evidence for effectiveness of home and school environments to support health food choices for children, and of breastfeeding. Modifying dietary intake to reduce overall energy intake while increasing energy output through physical exercise is an appropriate approach to weight management.

Cardiovascular disease is related to elevated serum LDL-cholesterol, diabetes and hypertension, all of which can be caused at least in part by obesity. Measures for which evidence is convincing, according to the Joint WHO/FAO Expert Consultation on Diet, Nutrition and the Prevention of Chronic Diseases, include regular physical activity, linoleic acid (omega-6 PUFA), DHA and EPA (omega-3 PUFA), vegetables and fruits, potassium, and low to moderate alcohol intake (2003). Conversely, increased risk is associated with saturated fatty acids, trans fatty acids, high sodium intake, overweight/obese, and high alcohol intake (stroke). 
Emir. J. Agric. Sci. 2003. 15 (2): 1-16

http://www.cfs.uaeu.ac.ae/research/ejas.html

Recommendations for Dietary Intake*

\section{BMI or Dietary Component}

Body mass index (BMI)

Total fat

Saturated fatty acids (SFA)

Polyunsaturated fatty acids (PUFA)

Omega-6 polyunsaturated fatty acids

Omega-3 polyunsaturated fatty acids

Trans fatty acids (TFA)

Monunsaturated fatty acids (MUFA)

Total carbohydrate

Protein

Naturally occurring and added sugars

Cholesterol

Sodium

Dietary fiber from fruits, vegetables, whole grain cereals

Fruits and vegetables

\section{Recommended level}

$18.5-24.9 \mathrm{~kg} / \mathrm{m}^{2}$

15 to $30 \%$ energy intake

less than $10 \%$ energy intake

6 to $10 \%$ energy intake

5 to $8 \%$ energy intake

1 to $2 \%$ energy intake

$<1 \%$ energy intake

[Total fat-SFA-PUFA-TFA]

55 to $75 \%$ energy intake

$<10 \%$ energy intake

10 to $15 \%$ energy intake

$<300 \mathrm{mg}$

$<2000 \mathrm{mg}$

$>25 \mathrm{~g}$

$\geq 400 \mathrm{~g}$

* Adapted from the Joint WHO/FAO Expert Consultation on Diet, Nutrition and the Prevention of Chronic Diseases (2003)

\section{Conclusion}

The food industry has marketed foods that are wanted by consumers, an appropriate business decision. However, in developed nations the opportunity to promote development of a food industry that focuses upon products that will enhance health, rather than compromise it, has arrived. To address the health problems that are endemic in a society of well-fed and overfed people who are interested in saving their own energy rather than expending it through physical activity, a public health education program must be coupled with the industry initiative. The examples of South Korea and Finland provide support for the concept that the nutrition transition can be impacted to reduce the increase in chronic disease.

Efforts should be directed toward promoting a food supply that contributes adequate amounts of nutrients and other dietary components, such as phytochemicals and fiber, which are helpful in maintaining optimal health and in delaying or preventing chronic disease. Biotechnology can be used to improve crop yield and to enhance nutritional value and content of substances, such as phytochemicals, in foods. Achieving the goal of optimal nutrition and health for all requires efforts of the food system from biotechnology and production to processing, distribution, and marketing.

\section{References}

Abdulrazzaq, Y. M., L. I. Al-Gazali, A. Bener, M. Hossein, M. Verghese, A. Dawodu and R. Padmanabham. 2003. Folic acid awareness and intake survey in the United Arab Emirates. Repro. Toxicol. 17:171-176. 
Abdulrazzaq, Y. M., A. Bener, A. Bawodu, I. Kappel, F. A. Surouri, E. Varady, L. Liddle, M. Varghese and M. Y. Cheema. 1995. Obstetric risk factors affecting incidence of low birth weight in live-born infants. Biol. Neonate 67:160-166.

Al-Mazroui, M. J., C. O. Oyejide, A. Bener and M. Y. Cheema. 1997. Breastfeeding and supplemental feeding for neonates in Al-Ain, United Arab Emirates. J. Trop. Pediatr. 43:304-306.

Amine, E. K. and M. Samy. 1996. Obesity among female university students in the United Arab Emirates. J. Roy. Soc. Health. 116:91-96.

Anderson, J. J. B. and H. E. Sjoberg. 2001. Dietary calcium and bone health in the elderly: uncertainties about recommendations. Nutr. Res. 21:263-268.

Badrinath, P., Q. A. Al-Shboul, T. Zoubeidi, A. S. Gargoum, R. Ghubash and O. E. ElRufaie (Eds). 2002. Measuring the health of the nation: United Arab Emirates Health and Lifestyle survey 2000. Faculty of Medicine \& Health Sciences and College of Business and Economics, UAE University, Al-Ain, United Arab Emirates.

Barker, D. J. P. 1998. Mothers, Babies, and health in later life. Harcourt Brace \& co. Ltd., Edinburgh.

Barler. D. J. P, J. G. Eriksson, T. Forsen and C. Osmond. 2002. Fetal origins of adult disease: strength of effects and biological basis. Int. J. Epidemiol. 31:1235-1239.

Barker, D. J., P. D. Winter, C. Osmond, B. Margetts and S. J. Simmonds. 1989. Weight in infancy and death from ischaemic heart disease. Lancet 8663:577-580.

Bener, A., Y. M. Abdulrazzaq and A. Dawodu. 1996. Sociodemographic risk factors associated with low birthweight in United Arab Emirates. J Biosoc. Sci. 28:339-346.

Bener, A., S. Denic and S. Galadari. 2001. Longer breast-feeding and protection against childhood leukaemia and lymphomas. Euro. J. Cancer 37:234-238.

Bener, A., S. Galadari, M. Gillett, N. Osman, H. Al-Taneiji, M. H. H. Al-Kuwaiti and M. M. A. Al-Sabosy. 2001. Fasting during the holy month of Ramadan does not change the composition of breast milk. Nutr. Res. 21:859-864.

Bener, A., G. G. Lestringant, A. Townsend, and H. M. Al-Mulla. 2001. Association of acanthosis nigricans with risk of diabetes mellitus, and hormonal disturbances in Arabian females: case-control study. Maturitas 40:53-59.

Bray, G. A. 2002. Predicting obesity in adults from childhood and adolescent weight. Am. J. Clin. Nutr. 76:497-498.

Bunduki, V., M. Dommergues, J. Zittoun, J. Marquet, F. Muller and Y. Dumez. 1995. Maternal-fetal folate status and neural tube defects: a case-control study. Biol. Neonate 67:154-159.

Cadogen, J., R. Eastell, N. Jones and M. E. Barker. 1997. Milk intake and bone mineral acquisition in adolescent girls: randomized, controlled intervention trial. BMJ 315:1255-1260. 
Czeizel, E. A. and I. Dudas. 1992. Prevention of the first occurrence of neural tube defects by periconceptional vitamin supplementation. N. Engl. J. Med. 327:1832-1835.

Dashti, B., F. Al-Awadi, W. Sawaya, J. AlOtaibi and A. Al-Sayegh. 2003. Fatty acid profile and cholesterol content of 32 selected dishes in the state of Kuwait. Food Chem. 80:377-386.

Dawodu, A., G. Absood, M. Patel, M. Agarwal, M. Ezimokhai, Y. Abdulrazzaq and G. Khalayli. 1998. Biosocial factors affecting vitamin D status of women of childbearing age in the United Arab Emirates. J. Biosoc. Sci. 30:431-437.

Dawodu, A., M. Agarwal, M. Hossain, J. Kochiyl and R. Zayed. 2003. Hypovitaminosis $\mathrm{D}$ and vitamin $\mathrm{D}$ deficiency in exclusively breast-feeding infants and their mothers in summer: a justification for vitamin $D$ supplementation of breast-feeding infants. J. Pediatr. 142:169-73.

Dawodu, A., K. P. Dawson, I. Amirlak, J. Kochiyil, M. Agarwal and P. Badrinath. 2001. Diet, clothing, sunshine exposure and micronutrient status of Arab infants and young children. Ann. Trop. Pediatr. 21:39-44.

Dietz, W. H., M. G. Bland, S. L. Gortmaker, M. Molloy and T. L. Schmid. 2002. Policy tools for the childhood obesity epidemic. J. Law Med. Ethics 30:82-87.

Dietz, W. H. 2001. Breastfeeding may help prevent childhood overweight. JAMA 285:2506-2507.
Drewnowski, A., B. M. Popkin. 1997. The nutrition transition: new trends in the global diet. Nutr. Rev. 55:31-43.

ElMugamer, I. T., A. S. Ali Zayat, M. M. Hossain and R. N. Pugh. 1995. Diabetes, obesity and hypertension in urgan and rual people of Bedouin origin in the United Arab Emirates. J. Trop. Med. Hyg. 98:407-415.

Eliasi, J. R. and J. T. Dwyer. 2002. Kosher and Halal: religious observances affecting dietary intakes. J. Am. Diet. Assoc. 102:911-913.

Eriksson, J. G., T. Forsen, J. Tuomilehto, C. Osmond and D. J. Barker. 2001. Early growth and coronary heart disease in later life: longitudinal study. BMJ 322:949953.

Eriksson, J. G., T. Forsen, J. Tuomilehto, C. Osmond and D. J. Barker. 2000. Early growth, adult income, and risk of stroke. Stroke 31:869-874.

Forsen, T., J. Eriksson, J. Tuomilehto, A. Reunanen, C. Osmond, D. Barker. 2000. The fetal and childhood growth of persons who develop type 2 diabetes. Ann. Intern. Med. 133:176-182.

Frankel S., P. Elwood, P. Sweetnam, J. Yarnell and G. D. Smith. 1996. Birth weight, body mass index in middle age, and incident coronary heart disease. Lancet 348:1478-1480.

Frankel, S., D. J. Gunnell, T. J. Peters, M. Maynard and G. D. Smith. 1998. Childhood energy intake and adult mortality from cancer: the Boyd Orr Cohort Study. BMJ 316:499-504. 
Galal, O. M. 2002. The nutrition transition in Egypt: obesity, undernutrition and the food consumption context. Pub. Health Nutr. 5:141-148.

Galtier-Dereure, F., C. Boegner and J. Bringer. 2000. Obesity and pregnancy: complications and cost. Am. J. Clin. Nutr. 71:1242S-1248S.

Gillman, M. W., S. L. Rifas-Shiman, C. A. Camargo, Jr., C. S. Berkey, A. L. Frazieer, H. R. Rockett, A. E. Field and G. A. Colditz. 2001. Risk of overweight among adolescents who were breastfed as infants. JAMA 285:2461-2467.

Godfrey, K. M. and D. J. P. Barker. 2000. Fetal nutrition and adult disease. Am. J. Clin. Nutr. 71:1344S-1352S.

Heber, D. and S. Bowerman. 2001. Applying science to changing dietary patterns. J. Nutr. 131:3078S-3081S.

Hossain, M. M., M. Bakir, R. N. Pugh, M. Sheekh-Hussen, S. A. Bin Ishaq, D. B. Berg and B. S. Lindblad. 1995. The prevalence and correlates of anaemia among young children and women of childbearing age in $\mathrm{Al}$ Ain, United Arab Emirates. Ann. Trop. Paediatr. 15:227235.

Jensen, G. L. and J. Rogers. 1998. Obesity in older persons. J. Am. Diet. Assoc. 98:1308-1311.

Joint WHO/FAO Expert Consultation on Diet, Nutrition and the Prevention of Chronic Diseases. 2003. Diet, nutrition and the prevention of chronic diseases: report of a joint WHO/FAO expert consultation, Geneva, 28 January-1 February 2002. WHO technical report series: 916. World Health Organization, Geneva, Switzerland. Internet: www.who.itn/hpr/NPH/docs/who-faoexpert-report.pdf Accessed June 17, 2003.

Kaiser, L. L. and L. Allen. 2001. Position of the American Dietetic Association: nutrition and lifestyle for a healthy pregnancy outcome. J. Am. Diet. Assoc. 102:1479-1490.

Khaldi, N. 1984. Evolving food gaps in the Middle East/North Africa: prospects and policy implications. Washington, D. C.: International Food Policy Research Institute.

Kim, W., S. Moon and B. M. Popkin. 2000. The nutrition transition in South Korea. Am. J. Clin. Nutr. 71:44-53.

Margolis, S. A., T. Carter, E. V. Dunn and R. L. Reed. The health status of community based elderly in the United Arab Emirates. Arch. Gerontol. Geriatr. 00:1-12.

Mills, J. L., J. M. McPartin, P. N. Kirke, Y. J. Lee, M. R. Conley, D. G. Weir and J. M. Scott. 1995. Homocysteine metabolism in pregnancies complicated by neural tube defects. Lancet 345:149151.

Murphy, E. W., A. C. Marsh and B. W. Willis. 1978. Nutrient content of spices and herbs. J. Am. Diet. Assoc. 72:174176.

Must, A. and R. D. Lipman. 1999. Childhood energy intake and cancer mortality in adulthood. Nutr. Rev. 57:2124. 
Musaiger, A. O. 1993. Socio-cultural and economic factors affecting food consumption patterns in the Arab countries. J. Roy. Soc. Health 113:68-74

Musaiger, A. O. 1994. Developing data on the composition of foods commonly consumed in Arabian Gulf countries: The experience in Bahrain. J Food Compos. Anal. 7:216-322.

Musaiger, A. O. and N. M. Abuirmeileh. 1998. Food consumption patterns of adults in the United Arab Emirates. J. Roy. Soc. Health 118:146-150.

Musaiger, A. O., A. Abdulghafoor and H. Radwan. 1996. Anaemia among 6 year old children in the United Arab Emirates. Euro. J. Clin. Nutr. 50:636-637.

Musaiger, A. O., M. A. Ahmed and M. V. Rao. 1998. Chemical composition of some traditional dishes of Oman. Food Chem. 61:17-22.

Musaiger, A. O. and H. M. Radwan. 1995. Social and dietary factors associated with obesity in university female students in United Arab Emirates. J. Roy. Soc. Health 115:96-99.

Must, A., P. F. Jacques, G. E. Dallal, C. J. Bajema and W. H. Dietz. 1992. Longterm morbidity and mortality of overweight adolescents. A follow-up of the Harvard Growth Study of 1922 to 1935. N. Engl. J. Med. 327:1350-1355.

Osman, N. A. and F. F. el-Sabban. 1999. Infant-feeding practices in Al-Ain, United Arab Emirates. E. Mediter. Health J. 5:103-110.

Plagemann, A., T. Harder, R. Kohlhoff, W. Rohde and G. Dorner. 1997. Overweight and obesity in infants of mothers with long-term insulin-dependent diabetes or gestational diabetes. Int. J. Obes. Relat. Metab. Disord. 21:451-456.

Popkin, B. M. 1993. Nutritional patterns and transitions. Popul. Dev. Rev. 19:138-157.

Pinhas-Hamiel, O. and P. Zeitler. 2000. "Who is the wise man? - the one who foresees consequences:" Childhood obesity, new associated comorbidity and prevention. Prev. Med. 31:702-705.

Pugh, R. N., M. M. Hossain, M. Malik, I. T. El Mugamer and M. A. White. 1998. Arabian Peninsula men tend to insulin resistance and cardiovascular risk seen in South Asians. Trop. Med. Int. Health 3:89-94.

Punnose, J., M. M. Agarwal, A. E. Khadir, K. Devadas and I. T. Mugamer. 2002. Childhood and adolescent diabetes mellitus in Arabs residing in the United Arab Emirates. Diab. Res Clin. Prac. 55:29-33.

Raisler, J. C. Alexander, and P. O'Campo. 1999. Breastfeeding: a dose-response relationship. Am. J. Pub. Health. 126:696702.

Roseboom, T. J., J. H. P. van der Meulen, A. C. J. Ravelli, C. Osmond, D. J. P. Barker and O. P. Bleker. 2001. Effects of prenatal exposure to the Dutch famine on adult disease in later life: an overview. Mol. Cel. Endocrin. 185:93-98.

Saadi, H. F., R. L. Reed, A. O. Carter, E. V. Dunn, H. S. Qazaq and A. r. Al-Suhaili. 2003. Quantitative ultrasound of the calceneus in Arabian women: relation to 
anthropometric and lifestyle factors. Maturitas 44:215-223.

Shahraban, A., K. Abdulla, B. Bjorksten and Y. Hofvander. 1991. Patterns of breast feeding and weaning in the United Arab Emirates. J. Trop. Pediatr. 37:13-16.

Sharief, N. M., S. Margolis and T. Townsend. 2001. Breastfeeding patterns in Fujairah, United Arab Emirates. J. Trop. Pediatr. 47:304-306.

Shatenstein, B. and P. Ghadirian. 1998. Influences on diet, health behaviours and their outcome in select ethnocultural and religious groups. Nutrition 14:223-230.

Shu, X. O., M. S. Linet, M. Steinbuch, W. Q. Wen, J. D. Buckley, J. P. Neglia, J. D. Potter, G. H. Reaman and L. L. Robison. 1999. Breast-feeding and risk of childhood acute leukemia. J. Nat. Cancer Inst. 91:1765-1772.

Singhal, A., T. J. Cole and A. Lucas. 2001. Early nutrition in preterm infants and later blood pressure: two cohorts after randomized trials. Lancet 357:413-419.

Srinivasan, S. R., W. Bao, W. A. Wattigney and G. S. Berenson. 1996. Adolescent overweight is associated with adult overweight and related multiple cardiovascular disk factors. The Bogalusa Heart Study. Metabolism 45:235-240.

Vartiainen, E., P. Puska, P. Jousilahti and H. J. Korhonen. 1999. Cardiovascular diseases and risk factors in Finland. Prev. Med. 29:S124-S129.

Von Kries, R., B. Koletzko, T. Sauerwald, E. von Mutius, D. Barnert, V. Grunert and H. von Voss. 1999. Breast feeding and obesity: cross sectional study. BMJ 319:147-150.

Walker, S. P., P. Gaskin, C. A. Powell, F. I. Bennett, T. E. Forrester and S. GranthamMcGregor. 2001. The effects of birth weight and postnatal linear growth retardation on blood pressure at age 11-12 years. J Epidemiol. Community Health 55:394-398.

Walker, S. P., P. S. Gaskin, C. A. Powell and F. I. Bennett. 2002. The effects of birth weight and postnatal linear growth retardation on body mass index, fatness and fat distribution in mid and late childhood. Pub. Health Nutr. 5:391-396.

Wang, Y., K. Ge and B. M. Popkin. 2000. Tracking of body mass index from childhood to adolescence: a 6-y follow-up study in China. Am. J. Clin. Nutr. 72:1018-1024.

World Cancer Research Fund \& American Institute for Cancer Research. 1997. Food, nutrition, and the prevention of cancer: a global perspective. American Institute for Cancer Research, Washington, D. C.

Young, V. R. 2002. 2001 W. O. Atwater Memorial Lecture and the 2001 ASNS President's Lecture: Human nutrient requirements: the challenge of the postgenome era. J. Nutr 132:621-629. 